\title{
Medidas de precisão experimental e número de repetições em ensaios de genótipos de arroz irrigado
}

\author{
Alberto Cargnelutti Filho(1), Enio Marchesan(1), Leandro Souza da Silva(2) e Marcos Toebe(1) \\ (1) Universidade Federal de Santa Maria (UFSM), Departamento de Fitotecnia, Avenida Roraima, no 1.000, Bairro Camobi, \\ CEP 97105-900 Santa Maria, RS. E-mail: cargnelutti@pq.cnpq.br, emarchezan@terra.com.br, m.toebe@gmail.com ${ }^{(2)}$ UFSM, Departamento \\ de Solos. E-mail: leandrosolos@ufsm.br
}

Resumo - O objetivo deste trabalho foi avaliar a adequação das estatísticas acurácia seletiva e valor do teste $\mathrm{F}$ para genótipo, como medidas do grau de precisão experimental, e determinar o número de medições (repetições) necessário à predição do desempenho de genótipos de arroz (Oryza sativa) irrigado. Foram utilizados dados de produtividade de grãos de 175 ensaios de competição de genótipos de arroz irrigado por alagamento. Os ensaios foram realizados no Estado do Rio Grande do Sul, de 1998 a 2011. Utilizou-se o delineamento de blocos ao acaso, com quatro repetições e número de genótipos entre 5 e 36. Foram realizadas análises de correlação e de trilha, e calculada a frequência de ensaios em cada classe de precisão experimental. Foram estimados os coeficientes de repetibilidade e calculado o número de repetições necessárias para predizer o valor real dos genótipos. As estatísticas acurácia seletiva e valor do teste F para genótipo são adequadas para avaliar a precisão experimental em ensaios de competição de genótipos de arroz irrigado. Ensaios com cinco repetições identificam genótipos superiores de arroz irrigado, com $82 \%$ de exatidão no prognóstico de seu valor real.

Termos para indexação: Oryza sativa, controle de qualidade, planejamento experimental, produtividade de grãos, repetibilidade.

\section{Measurements of experimental precision and number of replicates in rice genotype trials}

\begin{abstract}
The objective of this work was to evaluate the appropriateness of the statistics selective accuracy and F-test value for genotype, as measurements of the experimental precision degree, and to determine the number of measurements (replicates) necessary to predict the performance of irrigated rice (Oryza sativa) genotypes. Grain yield data from 175 genotype competition trials of rice irrigated by flooding were used. The trials were carried out in Rio Grande do Sul State, Brazil, from 1998 to 2011. The experimental design was a randomized complete block with four replicates and the number of genotypes between 5 and 36. Correlation and path analysis were performed, and the frequency of trials was calculated in each experimental precision class. To predict true genotypic values, the repeatability coefficients were estimated and the number of needed replicates was calculated. The statistics selective accuracy and F-test value for genotype are appropriate to evaluate the experimental precision of irrigated rice genotype trials. Trials with five replicates can identify superior irrigated rice genotypes, with $82 \%$ accuracy of the true prognostic value.
\end{abstract}

Index terms: Oryza sativa, quality control, experimental planning, grain yield, repeatability.

\section{Introdução}

Em programas de melhoramento genético de plantas, é comum comparar os genótipos em ensaios de campo. Nesses ensaios, é importante identificar diferenças, mesmo relativamente pequenas, entre genótipos do caractere em estudo, para selecionar os melhores genótipos e descartar os menos promissores. Para a adequada discriminação de genótipos, é fundamental que os ensaios tenham elevada precisão experimental.

Bases teóricas de estatísticas, como a acurácia seletiva e o valor do teste $\mathrm{F}$ para genótipo, foram discutidas por Resende (2002) e Resende \& Duarte
(2007). Esses autores consideraram essas estatísticas como adequadas para avaliar a precisão experimental de ensaios de competição de genótipos e estabeleceram faixas de precisão experimental. A ampliação desses estudos foi realizada em conjuntos de 101 ensaios de milho (Cargnelutti Filho \& Storck, 2007, 2009), 72 ensaios de feijão e 216 ensaios de soja (Cargnelutti Filho et al., 2009b). Todos os estudos foram concordantes e evidenciaram que essas estatísticas, entre outras, como herdabilidade, têm relação direta entre si e são apropriadas para avaliar a precisão experimental de ensaios de competição de genótipos de 
milho, feijão e soja. De modo geral, ficou demonstrado que, para esses ensaios de competição de cultivares, essas estatísticas, por estarem associadas a maiores variabilidades genéticas e, a menores variâncias residuais, são mais adequadas que o coeficiente de variação (Pimentel-Gomes, 1990; Costa et al., 2002) e que a diferença mínima significativa pelo teste de Tukey, em percentagem da média (Lúcio et al., 1999), comumente utilizadas para avaliar a precisão experimental.

A exploração dos resultados de um conjunto de ensaios éimportantepara avaliar a precisão experimental e adotar estratégias para melhorá-la, caso necessário. $\mathrm{O}$ dimensionamento do número de repetições adequado para certa precisão, fixada previamente pelo pesquisador, pode ser definido a partir desse conjunto de ensaios, por meio do coeficiente de repetibilidade. Estudos sobre o dimensionamento do número de repetições, com base em estimativas de coeficiente de repetibilidade, obtidas por meio do método da análise de variância (Cruz, 2006), foram realizados em feijão (Cargnelutti Filho et al., 2009a), em soja (Storck et al., 2009) e em milho (Cargnelutti Filho et al., 2010). Ao avaliar a produtividade de grãos dessas culturas, concluiu-se que: ensaios com quatro repetições possibilitam a identificação de cultivares superiores de feijão, com $85 \%$ de exatidão no prognóstico de seu valor real (Cargnelutti Filho et al., 2009a); ensaios com quatro repetições e analisados com o método de Papadakis possibilitam a identificação de genótipos superiores de soja, com $80 \%$ de precisão (Storck et al., 2009); e ensaios com três e quatro repetições identificam cultivares superiores de milho com, respectivamente, 72,4 e $81 \%$ de exatidão no prognóstico de seu valor real (Cargnelutti Filho et al., 2010).

Embora já conhecidas para algumas culturas, as estatísticas acurácia seletiva e valor do teste $\mathrm{F}$ para genótipo ainda não foram avaliadas em conjuntos de ensaios de genótipos de arroz (Oryza sativa L.) irrigado por alagamento. Também é desconhecida a precisão experimental, por essas estatísticas, dos ensaios de competição de genótipos de arroz irrigado. Adicionalmente, nenhuma referência ao uso da análise de repetibilidade para a estimativa do número de repetições na cultura do arroz irrigado foi encontrada na literatura consultada. As peculiaridades dessa espécie, em comparação a outras culturas avaliadas, e o ambiente de cultivo de irrigação por alagamento podem provocar efeitos distintos nos resultados dos ensaios, que justificam estudos dessa natureza com arroz irrigado.

O objetivo deste trabalho foi avaliar a adequação das estatísticas acurácia seletiva e valor do teste $\mathrm{F}$ para genótipo, como medidas do grau de precisão experimental, e determinar o número de medições (repetições) necessário à predição do desempenho de genótipos de arroz irrigado.

\section{Material e Métodos}

Foram usados os dados de produtividade de grãos, em kg ha-1, de 175 ensaios de competição de genótipos de arroz irrigado por alagamento, realizados no Estado do Rio Grande do Sul, no período de 1998 a 2011. Os dados foram obtidos em Anais do Congresso Brasileiro de Arroz Irrigado, em 1999, 2001, 2003, 2005, 2007, 2009 e 2011 (Tabela 1). Em todos os ensaios, os genótipos foram avaliados no delineamento de blocos ao acaso, com quatro repetições, e o número de genótipos variou de 5 a 36 . As unidades experimentais foram constituídas por nove ou dez fileiras, espaçadas em $0,175 \mathrm{~m}$, ou por dez fileiras espaçadas em $0,2 \mathrm{~m}$. Todas as unidades experimentais foram de $5,0 \mathrm{~m}$ de comprimento.

Em cada um dos 175 ensaios, com base na média de produtividade de grãos de cada genótipo, na média geral do ensaio $(\mathrm{m})$, no número de repetições $(\mathrm{J}=4)$ e no coeficiente de variação experimental, em percentagem $(\mathrm{CV})$, foram recalculadas as estatísticas: quadrado médio de genótipo,

$$
\mathrm{QM}_{\mathrm{G}}=\left(1 / \mathrm{J} \sum_{\mathrm{i}=1}^{\mathrm{I}} \mathrm{Y}_{\mathrm{i} .}-\mathrm{Y}^{2} . / \mathrm{IJ}\right) /(\mathrm{I}-1),
$$

em que: $Y_{i}$ é o total de produtividade de grãos das j-ésimas repetições do i-ésimo genótipo, e Y.. é o total de produtividade de grãos das j-ésimas repetições dos i-ésimos genótipos; e quadrado médio do erro,

$$
\mathrm{QM}_{\mathrm{E}}=(\mathrm{CV} \mathrm{m} / 100)^{2} \text {. }
$$

Em cada ensaio, foi estimada a diferença mínima significativa (DMS) entre as médias de genótipos, pelo teste de Tukey, a 5\% de probabilidade, expresso em percentagem da média, por meio da expressão: DMS $=100 \Delta / \mathrm{m}$, em que:

$$
\Delta=\mathrm{q}_{\alpha\left(\mathrm{n} ; \mathrm{GL}_{\mathrm{E}}\right)} \sqrt{\mathrm{QM}_{\mathrm{E}} / \mathrm{J}}
$$


e $\mathrm{q}_{\alpha\left(\mathrm{n} ; \mathrm{GL}_{\mathrm{E}}\right)}$ é o valor crítico para o uso do teste de Tukey; $\mathrm{n}$ é o número de genótipos; e $\mathrm{GL}_{\mathrm{E}}$ é o número de graus de liberdade do erro. Em seguida, foi determinado, para cada ensaio, o valor do teste $\mathrm{F}$ para genótipo $\left(\mathrm{Fc}=\mathrm{QM}_{\mathrm{G}} / \mathrm{QM}_{\mathrm{E}}\right)$ e o valor-p do teste $\mathrm{F}$ para genótipo. A acurácia seletiva (AS) foi estimada por meio da expressão: $\mathrm{AS}=(1-1 / \mathrm{Fc})^{0,5}$, conforme Resende (2002) e Resende \& Duarte (2007).

As avaliações em cada bloco foram consideradas como medições realizadas no mesmo indivíduo (genótipo), e foi estimado o coeficiente de repetibilidade (k), em cada ensaio, pelo método da análise de variância. $\mathrm{O}$ coeficiente de repetibilidade foi estimado por meio da expressão: $\mathrm{k}=\left[\left(\mathrm{QM}_{\mathrm{G}}-\mathrm{QM}_{\mathrm{E}}\right) / \mathrm{J}\right] /$ $\left.\left[\mathrm{QM}_{\mathrm{G}}-\mathrm{QM}_{\mathrm{E}}\right) / \mathrm{J}+\mathrm{QM}_{\mathrm{E}}\right]$, (Cruz \& Regazzi, 1997; Cruz, 2006).

Em relação às estatísticas $\mathrm{QM}_{\mathrm{G}}, \mathrm{QM}_{\mathrm{E}}, \mathrm{m}, \mathrm{CV}, \mathrm{DMS}$, $\mathrm{AS}, \mathrm{Fc}$ e k, obtidas para cada um dos 175 ensaios,

Tabela 1. Relação cronológica dos trabalhos científicos do Congresso Brasileiro de Arroz Irrigado, utilizados no presente trabalho.

\begin{tabular}{|c|c|c|c|c|c|}
\hline \multirow[t]{2}{*}{ Trabalho } & \multirow[t]{2}{*}{ Ano } & \multirow[t]{2}{*}{ Autores } & \multicolumn{2}{|c|}{ Página } & \multirow[t]{2}{*}{ № de ensaios } \\
\hline & & & Inicial & Final & \\
\hline 1 & 1999 & Rosso, A.F. et al. (1999a) & 76 & 77 & 4 \\
\hline 2 & 1999 & Lopes, S.I.G. et al. (1999a) & 78 & 81 & 5 \\
\hline 3 & 1999 & Lopes, S.I.G. et al. (1999b) & 82 & 84 & 4 \\
\hline 4 & 1999 & Lopes, S.I.G. et al. (1999c) & 85 & 88 & 9 \\
\hline 5 & 1999 & Rosso, A.F. et al. (1999b) & 95 & 96 & 2 \\
\hline 6 & 1999 & Terres, A.L. et al. (1999) & 162 & 165 & 7 \\
\hline 7 & 2001 & Franco, D.F. et al. (2001) & 69 & 71 & 5 \\
\hline 8 & 2001 & Lopes, S.I.G. et al. (2001a) & 89 & 91 & 10 \\
\hline 9 & 2001 & Lopes, S.I.G. et al. (2001b) & 92 & 93 & 8 \\
\hline 10 & 2001 & Lopes, S.I.G. et al. (2001c) & 94 & 96 & 7 \\
\hline 11 & 2001 & Rosso, A.F. et al. (2001) & 100 & 101 & 2 \\
\hline 12 & 2003 & Franco, D.F. et al. (2003) & 23 & 25 & 6 \\
\hline 13 & 2003 & Lopes, M.C.B. et al. (2003a) & 31 & 33 & 5 \\
\hline 14 & 2003 & Lopes, M.C.B. et al. (2003b) & 34 & 36 & 8 \\
\hline 15 & 2003 & Cruz, R.P. et al. (2003a) & 46 & 48 & 3 \\
\hline 16 & 2003 & Lopes, S.I.G. et al. (2003) & 52 & 54 & 8 \\
\hline 17 & 2003 & Cruz, R.P. et al. (2003b) & 67 & 69 & 2 \\
\hline 18 & 2005 & Lopes, S.I.G. et al. (2005) & 50 & 51 & 2 \\
\hline 19 & 2005 & Lopes, M.C.B. et al. (2005) & 75 & 77 & 8 \\
\hline 20 & 2005 & Franco, D.F. et al. (2005) & 145 & 148 & 10 \\
\hline 21 & 2007 & Fagundes, P.R.R. et al. (2007) & 35 & 37 & 6 \\
\hline 22 & 2007 & Lopes, M.C.B. et al. (2007a) & 102 & 104 & 7 \\
\hline 23 & 2007 & Cruz, R.P. et al. (2007) & 189 & 191 & 2 \\
\hline 24 & 2007 & Lopes, M.C.B. et al. (2007b) & 192 & 194 & 3 \\
\hline 25 & 2009 & Lopes, M.C.B. et al. (2009) & 104 & 107 & 5 \\
\hline 26 & 2009 & Fagundes, P.R.R. et al. (2009) & 123 & 126 & 10 \\
\hline 27 & 2011 & Lopes, M.C.B. et al. (2011) & 46 & 49 & 7 \\
\hline 28 & 2011 & Rosso, A.F. et al. (2011) & 54 & 57 & 5 \\
\hline 29 & 2011 & Fagundes, P.R.R. et al. (2011) & 129 & 132 & 6 \\
\hline 30 & 2011 & Lopes, S.I.G. et al. (2011) & 203 & 206 & 8 \\
\hline 31 & 2011 & Silva, M.G. et al. (2011) & 228 & 231 & 1 \\
\hline
\end{tabular}

foram calculados os valores mínimo e máximo, as medidas de tendência central (média e mediana) e a medida de dispersão (CV), tendo-se realizado o teste de normalidade de Kolmogorov-Smirnov (Siegel \& Castellan Júnior, 2006). Em seguida, foi calculado o coeficiente de correlação linear de Pearson (r), entre as estatísticas $\mathrm{QM}_{\mathrm{G}}, \mathrm{QM}_{\mathrm{E}}, \mathrm{m}, \mathrm{CV}$, DMS, AS e Fc, e a sua significância foi verificada por meio do teste $\mathrm{t}$ de Student, a 5\% de probabilidade. Foram realizados o diagnóstico de multicolinearidade (Cruz \& Carneiro, 2003) e a análise de trilha das variáveis principais, candidatas a medidas de precisão $(\mathrm{CV}, \mathrm{DMS}, \mathrm{AS}$ e $\mathrm{Fc})$, em função das variáveis explicativas $\left(\mathrm{QM}_{\mathrm{G}}, \mathrm{QM}_{\mathrm{E}}\right.$ e m). Posteriormente, com base em AS e Fc, foram calculadas as frequências simples e relativas de ensaios, nas classes de precisão experimental estabelecidas em Resende \& Duarte (2007).

O número mínimo de medições ou repetições (J) necessário para predizer o valor real dos indivíduos (genótipos), com base em coeficiente de determinação genotípico $\left(\mathrm{R}^{2}\right)$ pré-estabelecido em 0,81 , foi calculado por meio da expressão: $\mathrm{J}=\left[\mathrm{R}^{2}(1-\overline{\mathrm{k}})\right] /\left[\left(1-\mathrm{R}^{2}\right) \overline{\mathrm{k}}\right]$ (Cruz \& Regazzi, 1997), em que $\overline{\mathrm{k}}$ é a média dos coeficientes de repetibilidade $(\mathrm{k})$ dos 175 ensaios. A partir de $\overline{\mathrm{k}}$, calculou-se o $\mathrm{R}^{2}$ em função de diferentes números de repetições ( $\mathrm{J}$ com variação de 0 a 10 ), para mostrar graficamente o comportamento da relação entre $\mathrm{R}^{2}$ e J. O R ${ }^{2}$, que representa a certeza da predição do valor real dos genótipos selecionados, com base em $J$ medições realizadas, foi obtido pela expressão $\mathrm{R}^{2}=(\mathrm{J} \overline{\mathrm{k}}) /[1+\overline{\mathrm{k}}(\mathrm{J}-1)]$ (Cruz, 2006). As análises estatísticas foram realizadas com auxílio do programa Genes (Cruz, 2006) e do aplicativo Excel (Microsoft Office).

\section{Resultados e Discussão}

O efeito de genótipo foi significativo $(\mathrm{p} \leq 0,05)$ em 158 ensaios $(90,29 \%)$, o que indica que houve discriminação de genótipos quanto à produtividade de grãos de arroz irrigado por alagamento. Em conjuntos de 101 e 286 ensaios de milho (Cargnelutti Filho \& Storck, 2007; Cargnelutti Filho et al., 2009a) e de 216 ensaios de soja (Storck et al., 2009), o efeito de genótipo foi significativo, em relação à produtividade de grãos, respectivamente, em 92,08, 89,51 e 79,60\% dos ensaios. Nesses ensaios, o teste $\mathrm{F}$ da análise de variância evidenciou efeito significativo de genótipos, 
o que não qualifica o experimento como preciso, pois este teste indica apenas que o genótipo com maior média difere do genótipo com menor média e não revela a significância dos demais contrastes de médias de genótipos. Nos ensaios com valor-p do teste F para genótipo superior a 0,05 , não houve discriminação dos genótipos. O fato de não terem sido detectadas diferenças significativas entre genótipos pode ter sido decorrente da sua inexistência ou do erro experimental muito alto. Portanto, além da significância do teste $\mathrm{F}$ para genótipos, é importante classificar os experimentos por meio de estatísticas de precisão experimental.

A variabilidade existente $(13,78 \% \leq \mathrm{CV} \leq 109,30 \%)$ em relação às estatísticas $\mathrm{QM}_{\mathrm{G}}, \mathrm{QM}_{\mathrm{E}}, \mathrm{m}, \mathrm{CV}, \mathrm{DMS}$, AS, Fc e k, obtidas para cada um dos 175 ensaios, é importante e confere maior abrangência às inferências realizadas, por incluir cenários extremos (Tabela 2). Entre essas estatísticas, apenas os dados da média, da DMS e da repetibilidade se ajustaram à distribuição normal, de acordo com os valores-p do teste de Kolmogorov-Smirnov ( $p>0,05)$. As demais estatísticas $\left(\mathrm{QM}_{\mathrm{G}}, \mathrm{QM}_{\mathrm{E}}, \mathrm{CV}, \mathrm{AS}\right.$ e Fc) apresentaram valores-p do teste de Kolmogorov-Smirnov menores ou iguais a 0,05 . Embora a maioria das estatísticas não tenha se ajustado à distribuição normal, o elevado número de ensaios (175), aliado à variabilidade das estatísticas entre os ensaios, qualifica esse banco de dados para o estudo proposto.

$\mathrm{O}$ diagnóstico de multicolinearidade realizado na matriz de correlação linear de Pearson entre as estatísticas $\mathrm{QM}_{\mathrm{G}}, \mathrm{QM}_{\mathrm{E}}$ e média da produtividade de grãos revelou número de condição igual a três. Assim, a matriz de correlações é classificada como de colinearidade baixa, o que permite a realização adequada da análise de trilha (Cruz \& Carneiro, 2003; Cruz, 2006). Foram realizadas análises de trilha das variáveis principais, $\mathrm{CV}$, DMS, AS e Fc, em função das variáveis explicativas, $\mathrm{QM}_{\mathrm{G}}, \mathrm{QM}_{\mathrm{E}}$ e $\mathrm{m}$ (Tabela 3). De modo geral, os resultados das análises de trilha estão em concordância com os obtidos para produtividade de grãos de 101 ensaios de milho (Cargnelutti Filho \& Storck, 2007, 2009), 72 ensaios de feijão e 216 ensaios de soja (Cargnelutti Filho et al., 2009b).

Por meio das análises de trilha, verificou-se que as variáveis principais formaram dois grupos, com resultados semelhantes dentro dos grupos e distintos entre os grupos. O CV e a DMS formaram o primeiro grupo, e a AS e o Fc constituíram o segundo (Tabela 3). A elevada associação linear positiva entre CV e DMS ( $r=0,9861)$, a relação direta e não linear entre AS e Fc (Cargnelutti Filho \& Storck, 2009), e as relações lineares de baixa magnitude, embora significativas, entre as estatísticas dos grupos, ou seja, entre CV x AS ( $r=-0,2998), C V \times F c(r=-0,3114)$, DMS x AS $(\mathrm{r}=-0,3221)$ e DMS x Fc $(\mathrm{r}=-0,3595)$, reforçam a existência desses dois grupos de estatísticas (Figura 1). As inferências de Resende (2002), Cargnelutti Filho \& Storck (2007, 2009), Resende \& Duarte (2007) e Cargnelutti Filho et al. (2009b) sobre as diferenças entre esses grupos de estatísticas, utilizadas para avaliar a precisão experimental, foram confirmadas pelos resultados do presente trabalho. Esses autores observaram que as estatísticas AS e Fc são mais adequadas que o CV e a DMS, para avaliar a precisão experimental de ensaios de genótipos de milho, feijão e soja.

No conjunto de 175 ensaios de arroz irrigado, não houve associação linear entre o $\mathrm{QM}_{\mathrm{G}}$ e o CV $(\mathrm{r}=0,1253)$

Tabela 2. Mínimo, máximo, média, mediana, coeficiente de variação (CV) e valor p do teste de normalidade de Kolmogorov Smirnov das estatísticas dos dados de produtividade de grãos de 175 ensaios de competição de genótipos de arroz (Oryza sativa) irrigado por alagamento.

\begin{tabular}{|c|c|c|c|c|c|c|}
\hline Estatística $^{(1)}$ & Mínimo & Máximo & Média & Mediana & CV (\%) & valor-p \\
\hline$\overline{\mathrm{QM}_{\mathrm{G}}}$ & $249.400,00$ & $22.730 .817,11$ & $4.350 .631,77$ & $2.937 .659,12$ & 90,81 & 0,000 \\
\hline $\mathrm{QM}_{\mathrm{E}}$ & $41.400,85$ & $3.821 .677,02$ & $751.054,76$ & $619.983,01$ & 71,74 & 0,002 \\
\hline $\mathrm{m}$ & $4.030,00$ & $12.646,25$ & $8.416,12$ & $8.662,50$ & 21,47 & 0,165 \\
\hline $\mathrm{CV}$ & 2,88 & 21,66 & 9,95 & 9,00 & 32,24 & 0,008 \\
\hline DMS & 6,62 & 53,63 & 25,52 & 23,76 & 32,24 & 0,060 \\
\hline AS & 0,33 & 0,99 & 0,86 & 0,88 & 13,78 & 0,003 \\
\hline $\mathrm{Fc}$ & 1,12 & 65,72 & 7,17 & 4,52 & 109,30 & 0,000 \\
\hline $\mathrm{k}$ & 0,03 & 0,94 & 0,48 & 0,47 & 43,58 & 0,695 \\
\hline
\end{tabular}

(1) $\mathrm{QM}_{\mathrm{G}}$, quadrado médio de genótipo; $\mathrm{QM}_{\mathrm{E}}$, quadrado médio do erro; $\mathrm{m}$, média geral do ensaio; $\mathrm{CV}$, coeficiente de variação; DMS, diferença mínima significativa entre os genótipos, pelo teste de Tukey, a 5\% de probabilidade, expresso em percentagem da média; AS, acurácia seletiva; Fc, valor do teste F para genótipo; k, repetibilidade. 
e entre o $\mathrm{QM}_{\mathrm{G}}$ e a DMS ( $\left.\mathrm{r}=0,0618\right)$, com efeitos diretos desprezíveis do $\mathrm{QM}_{\mathrm{G}}$ sobre o CV $(0,0267)$ e a DMS $(-0,0445)$ (Tabela 3). Portanto, pode-se inferir que não há associação entre a variabilidade genética $\left(\mathrm{QM}_{\mathrm{G}}\right)$ e o CV e a DMS, o que indica que a classificação da precisão experimental por essas estatísticas é independente da variabilidade genética. No entanto, houve associação linear positiva entre o $\mathrm{QM}_{\mathrm{E}} \mathrm{e}$ as estatísticas CV $(r=0,7068)$ e DMS $(r=0,6933)$, e os efeitos diretos do $\mathrm{QM}_{\mathrm{E}}$ sobre o CV $(0,9391)$ e a DMS $(0,9416)$ foram de mesmo sinal que or e com magnitudes semelhantes, o que configura relação de causa e efeito entre o $\mathrm{QM}_{\mathrm{E}}$ e essas estatísticas. Também houve associação linear negativa entre a média e as estatísticas $\mathrm{CV}(\mathrm{r}=-0,2709)$ e DMS $(\mathrm{r}=-0,2735)$, e os efeitos diretos da média sobre o CV $(-0,6360)$ e a DMS $(-0,6155)$ foram altos e de mesmo sinal do $\mathrm{r}$, o que confirma a verdadeira relação linear existente. Esses resultados são indicativos de que experimentos mais precisos (menores escores de CV e de DMS) estão associados a menores variâncias residuais e a maiores médias de produtividade de grãos, e independem da variabilidade

Tabela 3. Estimativas dos coeficientes de correlação de Pearson e respectivas estimativas dos efeitos diretos e indiretos das estatísticas quadrado médio de genótipo $\left(\mathrm{QM}_{\mathrm{G}}\right)$, quadrado médio do erro $\left(\mathrm{QM}_{\mathrm{E}}\right)$ e média geral do ensaio $(\mathrm{m})$ sobre as estatísticas coeficiente de variação $(\mathrm{CV})$, diferença mínima significativa (DMS) pelo teste de Tukey, a 5\% de probabilidade, em percentagem da média, acurácia seletiva (AS) e valor do teste $\mathrm{F}$ para genótipo $(\mathrm{Fc})$, para os dados de produtividade de grãos de 175 ensaios de competição de genótipos de arroz (Oryza sativa) irrigado por alagamento.

\begin{tabular}{lccccc}
\hline Variável & Efeito & \multicolumn{4}{c}{ Variável principal } \\
\cline { 3 - 6 } & & $\mathrm{CV}$ & $\mathrm{DMS}$ & $\mathrm{AS}$ & $\mathrm{Fc}$ \\
\hline $\mathrm{QM}_{\mathrm{G}}$ & Direto & 0,0267 & $-0,0445$ & 0,6389 & 0,8648 \\
& Indireto via $\mathrm{QM}_{\mathrm{E}}$ & 0,3130 & 0,3139 & $-0,1566$ & $-0,1753$ \\
& Indireto via $\mathrm{m}$ & $-0,2144$ & $-0,2075$ & $-0,0202$ & $-0,0080$ \\
& Correlação de Pearson (r) & $0,1253^{\mathrm{ns}}$ & $0,0618^{\mathrm{ns}}$ & $0,4621^{*}$ & $0,6814^{*}$ \\
\hline $\mathrm{QM}_{\mathrm{E}}$ & Direto & 0,9391 & 0,9416 & $-0,4697$ & $-0,5259$ \\
& Indireto via QM & 0,0089 & $-0,0148$ & 0,2130 & 0,2883 \\
& Indireto via $\mathrm{m}$ & $-0,2412$ & $-0,2334$ & $-0,0227$ & $-0,0090$ \\
& Correlação de Pearson $(\mathrm{r})$ & $0,7068^{*}$ & $0,6933^{*}$ & $-0,2794 *$ & $-0,2466^{*}$ \\
\hline $\mathrm{m}$ & Direto & $-0,6360$ & $-0,6155$ & $-0,0599$ & $-0,0238$ \\
& Indireto via QM & 0,0090 & $-0,0150$ & 0,2154 & 0,2915 \\
& Indireto via QM & 0,3561 & 0,3571 & $-0,1781$ & $-0,1994$ \\
& Correlação de Pearson $(\mathrm{r})$ & $-0,2709^{*}$ & $-0,2735^{*}$ & $-0,0227^{\text {ns }}$ & $0,0683^{\text {ns }}$ \\
\hline & Coeficiente de determinação & 0,8393 & 0,8183 & 0,4279 & 0,7173 \\
& Variável residual & 0,4008 & 0,4262 & 0,7564 & 0,5317 \\
\hline
\end{tabular}

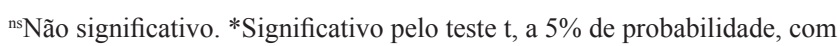
173 graus de liberdade. genética do grupo de genótipos avaliados no ensaio. Para ensaios de competição de genótipos, é importante que a estatística de precisão experimental contemple a variabilidade genética (Resende \& Duarte, 2007) e seja independente da média. Assim, as estatísticas CV e DMS, tradicionalmente utilizadas para essa finalidade, podem ser substituídas por outras estatísticas, como AS e Fc, apontadas como mais apropriadas (Resende, 2002; Cargnelutti Filho \& Storck, 2007, 2009; Resende \& Duarte, 2007; Cargnelutti Filho et al., 2009b).

Houve associação linear positiva entre o $\mathrm{QM}_{\mathrm{G}}$ e as estatísticas AS $(r=0,4621)$ e Fc $(r=0,6814)$, com efeitos diretos sobre AS $(0,6389)$ e Fc $(0,8648)$ de mesmo sinal que $r$ e com magnitudes semelhantes. Apesar dos valores baixos dos coeficientes de correlação linear de Pearson entre o $\mathrm{QM}_{\mathrm{E}}$ e as estatísticas AS $(\mathrm{r}=-0,2794)$ e Fc $(r=-0,2466)$, os efeitos diretos sobre AS $(-0,4697)$ e Fc $(-0,5259)$ foram maiores e de mesmo sinal, o que revela verdadeira associação linear negativa. Contudo, não houve correlação linear entre a média e a AS $(r=-0,0227)$ e o $F c(r=0,0683)$, e os efeitos diretos foram desprezíveis (Tabela 3). De acordo com esses resultados, ensaios mais precisos (maiores escores das estatísticas AS e Fc) estão associados a maiores variâncias genéticas e a menores variâncias residuais, e independem da média de produtividade de grãos. Essas características confirmam a adequabilidade dessas estatísticas como medidas de precisão experimental de ensaios de genótipos de arroz irrigado, como mostrado teoricamente em Resende \& Duarte (2007) e confirmado em ensaios de milho (Cargnelutti Filho \& Storck, 2007, 2009) e de feijão e soja (Cargnelutti Filho et al., 2009b). Embora essa generalização não possa ser feita, é provável que essas inferências confirmemse para ensaios de competição de genótipos de culturas em geral, pois o comportamento dessas estatísticas foi o mesmo em conjuntos de ensaios de milho, de feijão, de soja e, no presente trabalho, de arroz irrigado por alagamento. Portanto, é importante a realização de estudos com outras culturas antes da generalização do uso dessas estatísticas para a avaliação da precisão experimental de ensaios de competição de genótipos.

No presente trabalho, 90,86\% dos ensaios de competição de genótipos de arroz irrigado apresentaram precisão alta ou muito alta (AS $\geq 0,70$ e $\mathrm{Fc} \geq 1,9608$ ). Entretanto, 2,28\% dos ensaios poderiam ser descartados por apresentarem precisão experimental insuficiente (Tabela 4). Por meio dessas 
estatísticas, $89,10,88,89$ e $75 \%$, respectivamente, dos ensaios de competição de genótipos de milho (Cargnelutti Filho \& Storck, 2009), de feijão e de soja (Cargnelutti Filho et al., 2009b) apresentaram precisão alta ou muito alta. Esses mesmos autores também constataram que $4,95,2,78$ e $10,19 \%$ dos ensaios de milho, feijão e soja, respectivamente, poderiam ser descartados em virtude da baixa precisão experimental. Com esses resultados, evidenciouse que estratégias, como o redimensionamento do número de repetições, são importantes para melhorar a precisão experimental.

Entre os 175 ensaios, a estimativa do coeficiente de repetibilidade $(\mathrm{k})$, da produtividade de grãos, oscilou entre 0,03 e 0,94, com média de 0,48 (Tabela 2). Resultados semelhantes foram obtidos em feijão (Cargnelutti Filho et al., 2009a), soja (Storck et al., 2009) e milho (Cargnelutti Filho et al., 2010). Ensaios que apresentam menor coeficiente de repetibilidade requerem maior número de medições (repetições) para predizer o valor real de determinado caráter e vice-versa (Cruz \& Regazzi, 1997). A variabilidade das estimativas dos coeficientes de repetibilidade (k) entre os 175 ensaios resultou em variabilidade no número de repetições para um mesmo valor de $\mathrm{R}^{2}$. Isso indica que há necessidade de aplicação de planejamentos experimentais específicos por ensaio, o que, na prática, é difícil. Ao se considerar
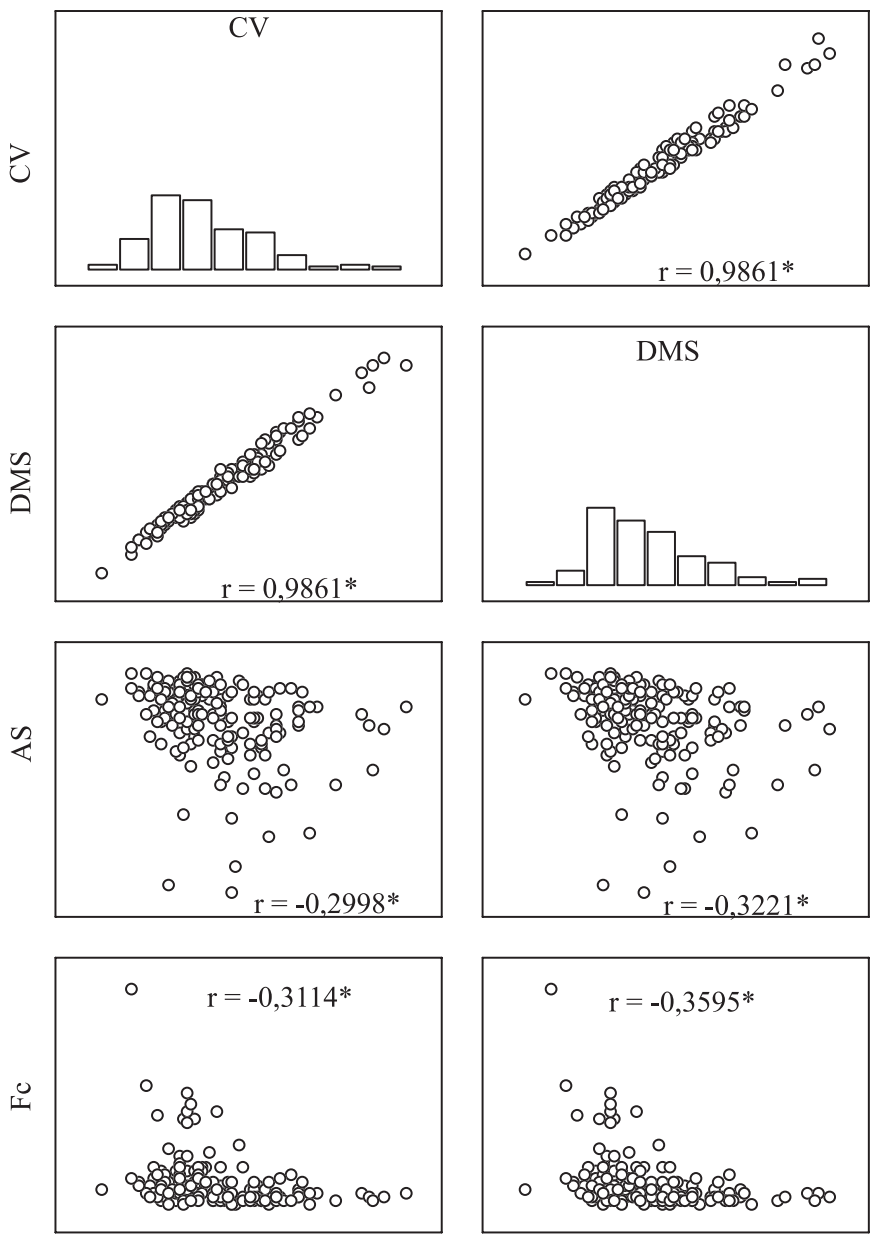

CV

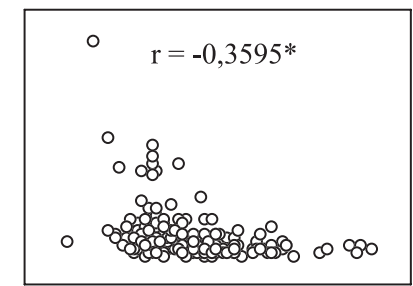

DMS
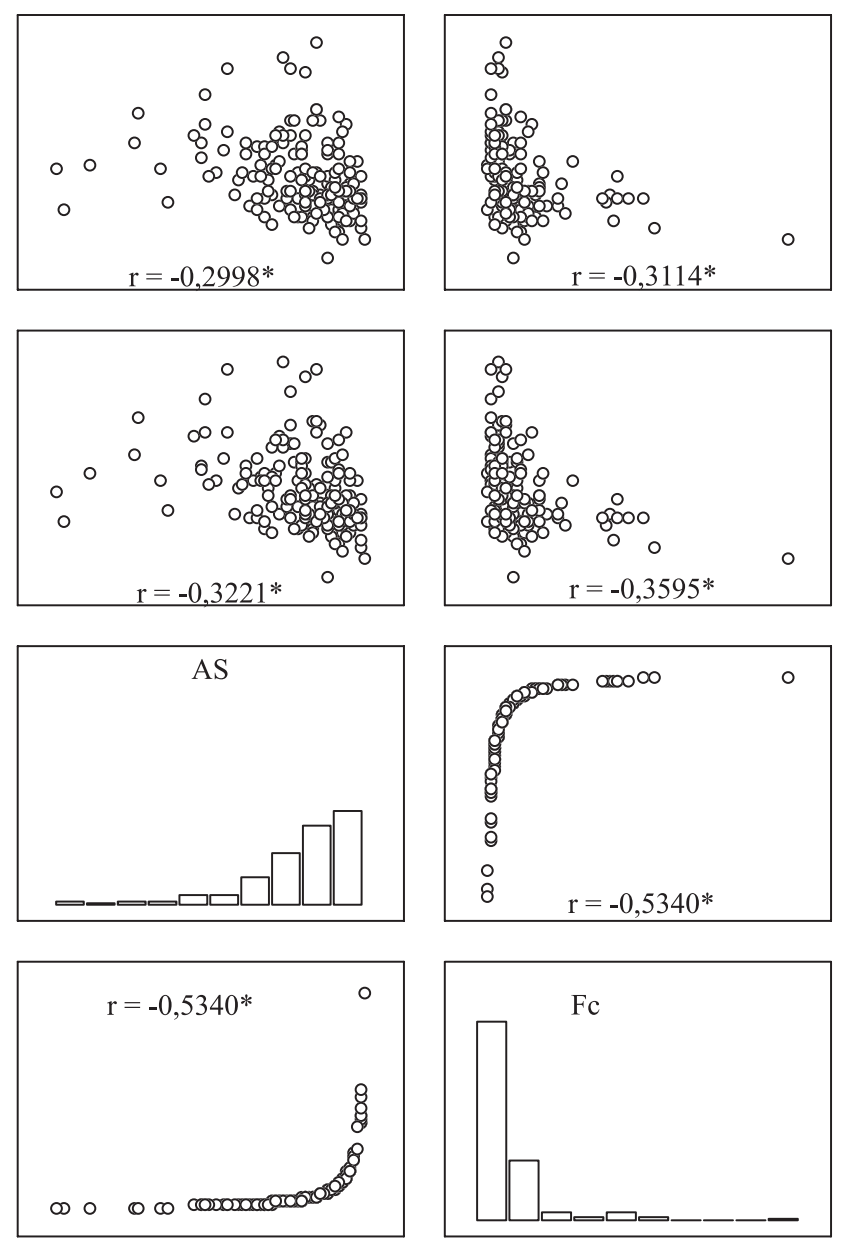

AS

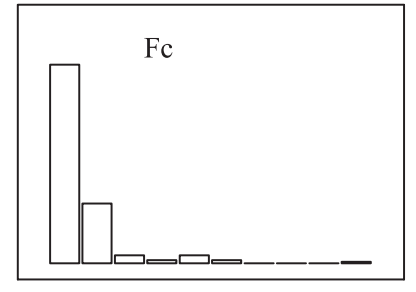

Fc

Figura 1. Matriz com a distribuição de frequência (na diagonal) e gráficos de dispersão entre as estatísticas coeficiente de variação $(\mathrm{CV})$, diferença mínima significativa (DMS) pelo teste de Tukey, a 5\% de probabilidade, em percentagem da média, acurácia seletiva (AS) e valor do teste F para genótipo (Fc) (fora da diagonal), e coeficientes de correlação de Pearson, obtidos de 175 ensaios de competição de genótipos de arroz (Oryza sativa) irrigado por alagamento, em relação à produtividade de grãos. *Significativo pelo teste t, a 5\% de probabilidade, com 173 graus de liberdade. 
que os dados dos 175 coeficientes de repetibilidade (k) ajustaram-se à distribuição normal (Tabela 2), parece adequado realizar uma abordagem geral, com base na média do coeficiente de repetibilidade, para contemplar de forma satisfatória um maior conjunto de ensaios.

Em relação à produtividade de grãos de arroz irrigado, que considera o coeficiente de repetibilidade (média dos 175 ensaios; $\overline{\mathrm{k}}=0,48$ ), seriam necessárias 4,62 repetições (na prática, igual a cinco repetições), ou seja, $\mathrm{J}=0,81(1-0,48) /(1-0,81) 0,48=4,62$, para afirmar, com $81 \%$ de precisão $\left(\mathrm{R}^{2}=0,81\right)$, a superioridade de um determinado genótipo, para as condições do Estado do Rio Grande do Sul. Ensaios com $\mathrm{R}^{2}$ igual ou superior a $81 \%$, isto é, com acurácia seletiva igual ou superior a 90\% (Resende \& Duarte, 2007), devem ser almejados, pois, nessa situação, seriam ensaios com precisão experimental muito alta. Entretanto, na prática, não é possível conduzir ensaios com 4,62 repetições. Assim, quando se realiza o cálculo inverso, a partir de $\mathrm{J}=4$ repetições, o valor estimado do coeficiente de determinação genotípico é $\mathrm{R}^{2}=(4 \times 0,48) /[1+0,48(4-1)]=0,79$, enquanto para $\mathrm{J}=5$ o $\mathrm{R}^{2}$ é 0,82 (Figura 2). Ao se considerar um valor médio para o coeficiente de repetibilidade $(\overline{\mathrm{k}}=0,48)$, pode-se inferir que é possível identificar genótipos superiores, em relação à produtividade de grãos, com precisão de 79 e $82 \%$, em ensaios com quatro e cinco repetições, respectivamente. Ganhos menores e inexpressivos em precisão são obtidos a partir de cinco repetições (Figura 1). Para avaliar a produtividade de grãos, ensaios com quatro repetições possibilitam a identificação de genótipos superiores de feijão (Cargnelutti Filho et al., 2009a), de soja (Storck et al., 2009) e de milho (Cargnelutti Filho et al., 2010), com, respectivamente, 85,80 e $81 \%$ de exatidão no prognóstico de seu valor real.

Na prática, particularmente nesses grupos de ensaios de milho, feijão, soja e arroz irrigado, realizados no Estado do Rio Grande do Sul, metas de acurácia seletiva de $90 \%$, o que equivale ao coeficiente de determinação genotípico de $81 \%$, têm sido obtidas com número de repetições relativamente menor que as seis repetições recomendadas, teoricamente, em Resende \& Duarte (2007). Entretanto, o uso de número maior de repetições deve ser encorajado para maximizar a precisão experimental.
Tabela 4. Limites das classes de precisão experimental, estabelecidos em Resende \& Duarte (2007), em relação à produtividade de grãos, para as estatísticas acurácia seletiva (AS) (Resende \& Duarte, 2007) e valor do teste F para genótipo (Fc) (Resende \& Duarte, 2007), e as frequências simples (fi) e relativa $\left(\mathrm{fr}_{\mathrm{i}}\right)$ de ensaios de competição de genótipos de arroz (Oryza sativa) irrigado por alagamento em cada classe.

\begin{tabular}{lcccc}
\hline Precisão experimental & $\mathrm{AS}^{(1)}$ & $\mathrm{Fc}^{(2)}$ & $\mathrm{f}_{\mathrm{i}}$ & $\mathrm{fr}_{\mathrm{i}}(\%)$ \\
\hline Muito Alta & $\geq 0,90$ & $\geq 5,2632$ & 76 & 43,43 \\
Alta & $\geq 0,70 \mathrm{e}<0,90$ & $\geq 1,9608 \mathrm{e}<5,2632$ & 83 & 47,43 \\
Moderada & $\geq 0,50 \mathrm{e}<0,70$ & $\geq 1,3333 \mathrm{e}<1,9608$ & 12 & 6,86 \\
Baixa & $<0,5$ & $<1,3333$ & 4 & 2,28 \\
\hline
\end{tabular}

${ }^{(1)} \mathrm{AS}=(1-1 / \mathrm{Fc})^{0,5} \cdot{ }^{(2)} \mathrm{Fc}=1 /\left(1-\mathrm{AS}^{2}\right)$.

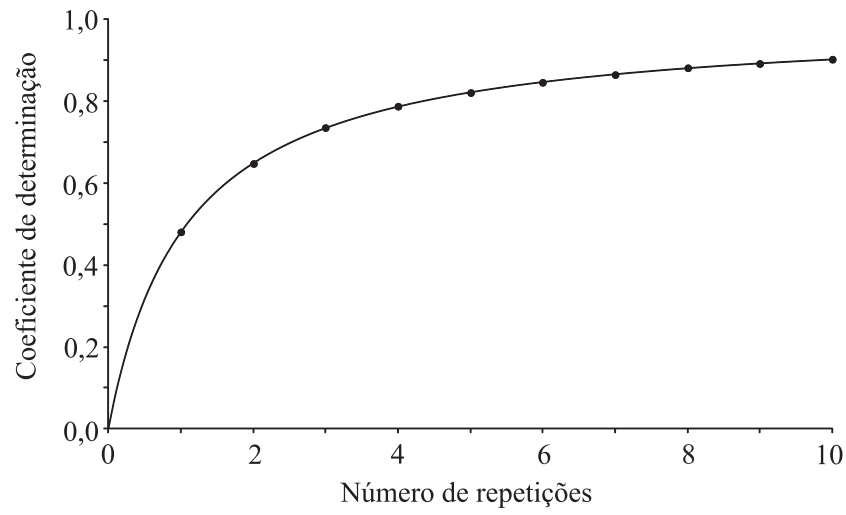

Figura 2. Estimativa dos coeficientes de determinação genotípico $\left(\mathrm{R}^{2}\right)$, da produtividade de grãos, em função do número de medições (repetições) (J), com base no coeficiente de repetibilidade $(\overline{\mathrm{k}}=0,48)$ médio de 175 ensaios de competição de genótipos de arroz (Oryza sativa) irrigado por alagamento.

\section{Conclusões}

1. As estatísticas acurácia seletiva e valor do teste F para genótipo são adequadas para avaliar a precisão experimental em ensaios de competição de genótipos de arroz irrigado.

2. No Estado do Rio Grande do Sul, ensaios com cinco repetições identificam genótipos superiores de arroz irrigado, em relação à produtividade de grãos, com $82 \%$ de exatidão no prognóstico de seu valor real.

\section{Agradecimentos}

Ao Conselho Nacional de Desenvolvimento Científico e Tecnológico e à Coordenação de Aperfeiçoamento de Pessoal de Nível Superior, pela concessão de bolsas. 


\section{Referências}

CARGNELUTTI FILHO, A.; RIBEIRO, N.D.; STORCK, L. Número de repetições para a comparação de cultivares de feijão. Ciência Rural, v.39, p.2419-2424, 2009a.

CARGNELUTTI FILHO, A.; STORCK, L. Estatísticas de avaliação da precisão experimental em ensaios de cultivares de milho. Pesquisa Agropecuária Brasileira, v.42, p.17-24, 2007.

CARGNELUTTI FILHO, A.; STORCK, L. Medidas do grau de precisão experimental em ensaios de competição de cultivares de milho. Pesquisa Agropecuária Brasileira, v.44, p.111-117, 2009.

CARGNELUTTI FILHO, A.; STORCK, L.; GUADAGNIN, J.P. Número de repetições para a comparação de cultivares de milho. Ciência Rural, v.40, p.1023-1030, 2010.

CARGNELUTTI FILHO, A.; STORCK, L.; RIBEIRO, N.D. Medidas da precisão experimental em ensaios com genótipos de feijão e de soja. Pesquisa Agropecuária Brasileira, v.44, p.1225-1231, 2009b.

COSTA, N.H. de A.D.; SERAPHIN, J.C.; ZIMMERMANN, F.J.P. Novo método de classificação de coeficientes de variação para a cultura do arroz de terras altas. Pesquisa Agropecuária Brasileira, v.37, p.243-249, 2002.
CRUZ, C.D. Programa Genes: Biometria. Viçosa: UFV, 2006. 382p. CRUZ, C.D.; CARNEIRO, P.C.S. Modelos biométricos aplicados ao melhoramento genético. Viçosa: UFV, 2003. v.2, 585p.

CRUZ, C.D.; REGAZZI, A.J. Modelos biométricos aplicados ao melhoramento genético. 2.ed. Viçosa: UFV, 1997. 390p.

LÚCIO, A.D.; STORCK, L.; BANZATTO, D.A. Classificação dos experimentos de competição de cultivares quanto a sua precisão. Pesquisa Agropecuária Gaúcha, v.5, p.99-103, 1999.

PIMENTEL-GOMES, F. Curso de estatística experimental. 13.ed. Piracicaba: Nobel, 1990. 468p.

RESENDE, M.D.V. de. Genética biométrica e estatística no melhoramento de plantas perenes. Brasília: Embrapa Informação Tecnológica; Colombo: Embrapa Florestas, 2002. 975p.

RESENDE, M.D.V. de; DUARTE, J.B. Precisão e controle de qualidade em experimentos de avaliação de cultivares. Pesquisa Agropecuária Tropical, v.37, p.182-194, 2007.

SIEGEL, S.; CASTELLAN JÚNIOR, N.J. Estatística não-paramétrica para ciências do comportamento. 2.ed. Porto Alegre: Artmed, 2006. 448p.

STORCK, L.; CARGNELUTTI FILHO, A.; LÚCIO, A.D.; LOPES, S.J. Método de Papadakis e número de repetições em experimentos de soja. Ciência Rural, v.39, p.977-982, 2009. 